\title{
ENTRECRUZANDO CORPOS, RAÍZES E MEMÓRIAS: ATRAVESSAMENTOS, EXPERIÊNCIAS E DESLOCAMENTOS NO ENCONTRO COM O OUTRO
}

\section{INTERWEAVING BODIES, ROOTS AND MEMORIES: CROSSINGS, EXPERIENCES AND DISPLACEMENTS WHILE ENCOUNTERING OTHERS}

\author{
Daniel Santos Costa ${ }^{1}$ \\ Tiago Samuel Bassani
}

\begin{abstract}
Resumo: Esta é uma narrativa escrita a quatro mãos embasada em uma vivência de deslocamento de territórios. As linhas que seguem no texto são construídas a partir da rememoração de uma experiência obtida com as pessoas, especificamente com Dona Maria da Aroeira, e ainda das memórias guardadas nos nossos corpos. Sobre estas, trazemos detalhes visuais mnemônicos, corporalidades e reminiscências para refletir sobre atravessamentos, experiências e potencialidade de um encontro.
\end{abstract}

Palavras-chave: Corpos; encontros; experiência; memória.

\begin{abstract}
This is a four-handed narrative written based on an experience of territory-shifting. The following lines are built from the recollection of people's experiences, specifically the recollection of Dona Maria da Aroeira, but also the memories stored in our bodies. From such memories we bring mnemonic visual details, corporealities and reminiscences in order to think about crossings, experiences and the potentiality of an encounter.
\end{abstract}

Keywords: Bodies; encounters; experiences; memory.

A proposta de escrever este texto a quatro mãos se deu por meio de dois fatores primordiais: encontros e distanciamentos vividos em um espaço-tempo que atravessou estados, cidades, comunidades, rios e paisagens; posterior rememoração de experiências que este deslocamento confluiu. Entre os dias 14 a 17 de julho de 2019 estivemos imersos nas atividades do $3^{o}$ Ateliê Integrado - Rios Urbanos, Arte, Cidade \& Comunidades realizado pelo curso de Artes Visuais da Universidade Federal do Oeste da Bahia (UFOB) ${ }^{3}$.

Tal proposição estava fundada em princípios inter/transdisciplinares de intensa interação com a comunidade local. Permear esse território nos presenteou com encontros pontuais, coletivos, intencionais e espontâneos, uma condição fecunda para entrelaçar histórias e memórias, para poder ouvir e compartilhar nossas vivências. A fim de compor este texto, evocamos as memórias guardadas no corpo que a experiência de ser/estar ajuntados àquelas pessoas nos proporcionou. Entre muitos encontros que desfrutamos, destacamos um em especial que marcou nossos corpos, habitou e instigou nossas percepções, o com a Dona Maria da Aroeira, que será retratado nas linhas seguintes. O desafio em tecer este texto está em como compreender o que é de fato um encontro com o outro e quais são os desdobramentos, afetos, memórias e como tudo isso se inscreve em nós.

\footnotetext{
${ }^{1}$ Universidade Federal de Uberlândia, Uberlândia, MG, Brasil.

${ }^{2}$ Universidade Federal do Oeste da Bahia (UFOB). Santa Maria da Vitória, BA, Brasil.

${ }^{3}$ A Universidade Federal do Oeste da Bahia - UFOB, possui o curso de Artes Visuais lotado na cidade de Santa Maria da Vitória - BA, que faz parte do Território de Identidade do Rio Corrente, um dos 27 Territórios de Identidade do estado da Bahia. Ele leva este nome porque engloba as cidades que são atravessadas pelo Rio Corrente um afluente que desagua no Rio São Francisco.
} 


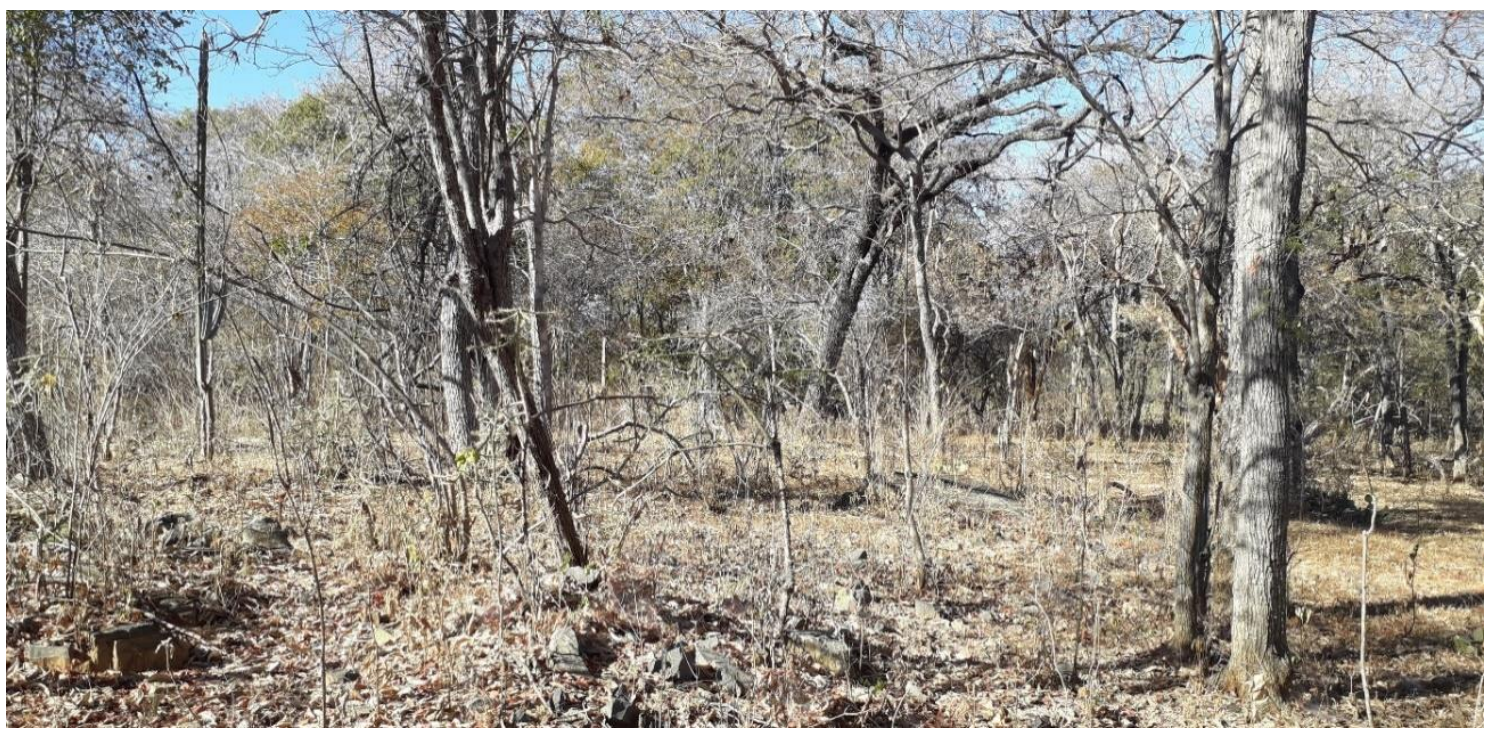

Fig. 1 - Árvores-raízes - Fonte: Arquivo dos autores

A peregrinação pelo oeste baiano confluiu em um encontro com um saber instituído na relação que alguns habitantes adquirem e guardam com a natureza. É o caso de Dona Maria da Aroeira, raizeira, moradora da zona rural da cidade de Correntina, que tem como ofício a extração das plantas locais para cuidados da saúde. Para além do seu ofício, habita em Dona Maria uma compreensão sobre um domínio que ultrapassa uma faculdade objetiva e se sustenta na ancestralidade, ou seja, nas transferências dos saberes pelos que a antecederam.

Em um domingo à tarde, adentramos algumas estradas de terra, assim como muitas da região, com empenho de localizar sua morada. Tratava-se de uma das ações planejadas na residência proposta pela comunidade e na busca, percebíamos os caminhos com alguma semelhança, por isso deambulamos um bom tempo pelas estradas entrecruzadas até alcançar sua casa. Antes da chegada, alicerçamos oralidades efêmeras com a nossa acompanhante, Conchita, moradora do município, discente do curso de Artes Visuais da UFOB, conhecedora dos saberes, fazeres e práticas da Dona Maria da Aroeira.

Saímos de Santa Maria da Vitória em direção a Correntina, um trajeto de aproximadamente 55 quilômetros. Conchita nos esperava em sua casa em um domingo de calor ameno. Sua família estava reunida festivamente comemorando, talvez, a singela condição de estarem juntos mais um final de semana. As direções nos foram dadas como quem orienta o outro pela oralidade - nas tessituras de voz, na intencionalidade e direção dos gestos. Atentamonos às diretrizes específicas que, em alguns momentos, faziam sentido somente para quem ali se enraizava. Dialetos, sotaques, jargões saltam aos olhos e lançaram luzes à nossa presença estrangeira em tal território. Entretanto, como Conchita nos mostraria os caminhos, estávamos seguros e bem orientados para seguirmos outra parte do trajeto pelas estradas de terra.

Rumamos em direção à casa de Dona Maria da Aroeira, personalidade emblemática na região. As notícias que tínhamos sobre ela adivinham de outras visitas de colegas da Universidade, de seu oficio como raizeira que se perpetua naquele território, fazendo-se cotidianamente presente no mercado público da cidade. Seguimos, individualmente, cada qual com uma imagem que fazíamos das histórias ouvidas, das experiências dos que a haviam visitado e dos vestígios e resquícios das memórias de tantos outros.

Diante da imagem que criávamos acerca dos elementos indiciais que nos foram apresentados, vislumbrávamos, cada um a seu modo, a imagem de uma mulher imponente 
frente à força que é destinada à árvore aroeira tal qual nos diz a canção Aroeira, de Sérgio Pererê $\hat{}^{4}$, presente no imaginário popular e detentora de inúmeros segredos e mistérios.

(...)

Dá licença cumadre Aroeira

Pra eu entrar na sua casa

Pedir que a Jurema me diga

Quando é que urubu cria asa

Me conta cumadre Aroeira

Como é que o nó se desata

Se for confirmado com junco

Do brejo da boca da mata

\section{(...)}

Munidos de tais impressões que nos foram constituindo, seguimos entre prosas e silêncios com nossa acompanhante que, por sua vez, fazia-nos embrenhar em caminhos errôneos, dada a dificuldade de acessar o local. Também contribuíram para nossa aparente desorientação, os inúmeros caminhos que por ali se encruzilhavam nas estradas de terra, mas um deles nos fez chegar a uma fazenda. Ali, um funcionário e o proprietário nos recepcionaram, respondendo a indagação dos que estavam perdidos. Os dentes de ouro de um dos homens nos direcionaram com certa desconfiança à casa de Maria da Aroeira, filha do Zé Aroeira. Tal nomeação nos remete à história que Negreiros (2018) conta sobre as mulheres serem conhecidas como propriedades de seus pais. A autora constrói uma brilhante narrativa sobre a vida de Maria Bonita, conhecida por Maria de Déa, tal qual Maria da Aroeira. Esta, mesmo sendo figura emblemática no entorno, ainda era remetida a uma figura masculina, seu pai. Tal situação nos rememora e aflora o contexto patriarcal ainda eminente, principalmente nos interiores das paisagens territoriais brasileiras.

$\mathrm{Na}$ travessia do caminho, uma experiência de encontros com singelas histórias da região se concretiza ouvindo delicadas narrativas emanadas por Conchita entremeando passado e presente em um Corpo Mnemônico. Corpo esse que se movimenta e é movimentado por um fluxo ininterrupto tal qual um rio corrente que, ao seguir caminhos desconhecidos, deságua em alguma paragem (COSTA, 2018). E assim, nas corredeiras da memória, nossa companhia nos brindava com gotas de histórias que a constituíam parte deste espaço. Lembra-se das caminhadas com a mãe nos emaranhados de terra, casas e taperas que compunham a paisagem. Em dado momento, ela nos atenta para a separação da vegetação do cerrado e o início da caatinga, expondo-nos ao contato com as histórias de luta pela terra na região. Desse lugar, insurgiam histórias da forte presença do agronegócio, sendo que um de seus indícios seria a falta d'água, muito sentida por meio dos tantos riachos secos que atravessamos.

Vamos adentrando o local pretendido após um tempo de caminhada que serviu para nos vincular às histórias perenes que compõe este lugar, afinal, erámos estrangeiros em terras nordestinas. Avistando a moradia de Dona Maria, atravessamos a porteira e adentramos em suas terras. Sua casa era cercada por outras, o que compunha uma vista de um lugarejo cravado em meio ao cerrado. Divisamos, saindo pelo umbral da porta, uma senhora que vestia um colorido alegre de flores e estampas. Perguntamos, e ela se apresentou como Dona Maria da Aroeira que ao nos cumprimentar, convidando-nos gentilmente para entrar em sua casa.

${ }^{4}$ PERERÊ, Sergio. Aroeira. Disponível em: 〈https://www.youtube.com/watch?v=GBJMf1rtPtI $>$. Acesso em: 25 nov. 2019. 
A senhora veio até nossa direção, pisada por pisada, com um olhar desajeitado e o corpo, aparentemente, frágil. Rememorar este encontro nestas escrituras nos demostra a pertinência da descolonização do imaginário, proposições paulatinamente defendidas por Boaventura de Souza Santos que nos provoca sobre as Epistemologias do Sul (SANTOS \& MENESES, 2010). Além deste, Walter Mignolo sobre a pertinência e necessidade de um giro decolonial como uma abertura para novas formas de vida (2007). Tais apontamentos nos revelam a contaminação de nosso imaginário por um processo de colonização que idealizava a figura da raizeira e nos confrontou com um estado de presença comunal. Dona Maria lembrava tantas outras senhoras com as quais já convivemos, distanciada de uma aura sobrenatural.

Sua voz trasbordava afeto e doçura, suas vestes destoavam do senso comum da combinação de cores e usava um lenço na cabeça com estampa de onça. A delicadeza emanada da voz que nos convidava a entrar na casa sem muito saber o que fazíamos por ali. Seguramente, havia um acordo muito bem estabelecido, pois estávamos com Conchita, conhecida pela velha senhora desde a infância da menina. E, assim, adentramos o espaço da casa, um verde vivo incomum, abrindo um espaço de comunicação afetivo. Sua performance nos fazia perceber que a visita por ali era algo rotineiro. A recepção era feita tal qual um protocolo já roteirizado que é muito bem constituído em seu Corpo Mnemônico, o que nos remete a perspectiva apontada por Diana Taylor (2013, p. 163) sobre memórias incorporadas que podem ser estratégias de sobrevivência e que incluem práticas performativas vinculadas as práticas ritualísticas, linguísticas e corporais.

Sentamos ao lado de seu filho no sofá que compunha a sua sala, tendo Conchita do outro lado. Dona Maria sentou à nossa frente em um tamborete próximo à mesa, cruzando as pernas acariciando as mãos com frequência. O cenário já estava destinado à entrevista que certamente ela esperava, ainda que tal vista tivesse acontecido de modo inesperado. A televisão estava ligada em um programa dominical e era assistida entre pelo filho de Dona Maria entremeada à atenção destinada aos diálogos estabelecidos. Permeando tudo, as paragens das conversas que deixava bolsões de silêncios que compunham muitas percepções do que havia sido dito até o momento.

O propósito de tal encontro era, certamente, conhecer um pouco das práticas da raizeira, muito divulgadas por alguns habitantes da cidade e que haviam se tornado visíveis no ambiente da Universidade. Buscávamos uma aproximação entre os saberes populares que nos possibilitassem, na medida do possível, descolonizar pensamentos, práticas descortinando novos mundos como bem nos provoca Acosta (2016) na sua proposição de Bem Viver como uma maneira de imaginar outros mundos.

Tal propósito coaduna com nossa atuação presente em espaços da oralidade popular brasileira (BASSANI, 2019; COSTA, 2019, 2017, 2010) e com uma estratégia que busca, no encontro com o outro, uma postura que evidencia e dá visibilidade para novos modos de concepção de mundo em condutas que se propõem plurais, coletivas e em coexistência. Portanto, esse foi o procedimento que adotamos ao atravessar as encruzilhadas que nos levaram à Dona Maria da Aroeira. De tal lugar, fomos atravessados por uma experiência que se impregna nos poros e vai nos constituindo Corpo Mnemônico, atravessados de histórias, acontecimentos e outras tantas narrativas corporais.

Voltando ao momento do encontro com Dona Maria, o suco de limão nos oferecido estava bem docinho e guardava um colorido típico de fruta apanhada do pé ali do seu quintal. O sabor do refresco nos concedia intervalo entre as perguntas e respostas que bradávamos e éramos indagados, especialmente da localidade de onde nos remetemos. Em dado momento da conversa, Dona Maria, como quem busca uma semelhança em alguém próximo, localiza em um de nós a aparência com o padre da região. Tal fato foi confirmado por um vaqueiro, amigo da família, que passou por ali à cavalo. Esse sujeito fez estender a conversa final sobre o alpendre da casa e rememorar os jiraus que guardavam algumas raízes que estavam a secar. 
Do outra lado da sala, lá da cozinha, pronunciava a voz de uma de suas filhas que habita uma das casas ali no terreno. Ela trabalhava do outro lado do único cômodo em que estivemos presentes e atravessava algumas vezes nossa conversa com direcionamentos familiares à mãe $\mathrm{e}$ não apareceu em nenhum momento para nos apresentarmos. Do lado de fora da casa, duas crianças brincavam mostrando intimidade com o espaço marcadamente rural, com a terra, com as árvores, descortinando um universo no qual também nos ambientamos na infância. Assim como o poeta Manoel de Barros, também ancoramos raízes no lugar materno da terra, sagrado e inaugural. Desse lugar, tecemos a compreensão que nela somos enraizados e na proclamação de um corpo-terra pautado na anciã figura dos avós, figuras primordiais no contexto das corporalidades populares brasileiras, tanto festivas quanto sociais.

A projeção do cenário, que no breve momento constituímos, faz-nos girar na compreensão de que raízes nos permitem voar, fabular nossas jornadas, espiralando presente, passado e futuro em um movimento sempre aberto. Seguimos a conversar com dona Maria até que a prosa foi tomada por uma atenção sobre sua história, seus fazeres compreendendo uma intimidade com a terra e os saberes que dela originaram. Desse lugar, das raízes, no sentido literal e metafórico, sua jornada era constituída. Parecia-nos que Dona Maria havia brotado tal qual uma planta que enraízase em determinado lugar, já que ela não havia nascido naquela localidade. Entretanto, as suas raízes profundas emaranhavam-se naquele pedaço de terra no oeste baiano.

Embrenhar essas narrativas através das memórias evidencia o caráter fugidio da tentativa de captura. Não intentamos tal objetivo pois ao atrevermos reescrever as experiências, conjugamo-nos no presente pois a experiência está constituída no corpo e apenas parte dela pode saltar-se em escritura, especialmente uma escritura coletiva que se faz a quatro mãos. Nossas experiências são distintas e nos atravessam corporalmente de modo particular, fazendo com que essas danças em palavras atuem como se pudéssemos voltar e presenciar o lapso do tempo no corpo. Mais que descrever e analisar Dona Maria da Aroeira, o presente diz sobre quem somos nós. Voltar para tal dimensão evidencia o caráter de alteridade que estabelecemos entre o eu e o outro, um jogo festivo de identidades (HALL, 2011) realizam uma experiência com o deslocamento e com o desconhecido.

O conhecimento da nossa entrevistada sobre as raízes e as propriedades curativas tornouse um propósito em sua vida. Um sentimento que despontou em si como curiosidade, quando ainda era criança e se desenrolou nos processos de amadurecimento, quase como a decantação de um preparado que vai se adensando ao longo do tempo. O conhecimento do fazer ia se incorporando à sua identidade até se tornar parte do seu nome, Aroeira.

Não por acaso, Dona Maria conta que na estrada da sua casa, na zona rural, havia uma árvore Aroeira altiva. Sua identificação carregava a referência da árvore também por estar plantada na direção da sua habitação. Quando as pessoas se referiam a ela e sua morada tomavam como orientação a árvore. Assim dialogavam: "Que Maria?", tendo como resposta: "A Maria da Aroeira". A incorporação da árvore como singular identificação distinguia, dentre tantas Marias da comunidade, sua singularidade, incorporando a árvore ao seu nome, à sua morada e como referência de uma vida.

A imagem de uma árvore que no meio do cerrado, sob um sol intenso, guarda desenhado debaixo dela uma sombra que acolhe gente, bicho e brisa, se fez muito presente nas palavras que prosseguiam a contação de sua história/memória. Dona Maria destaca seu carinho com a família e nos mostrava, para além da janela da sala, as casas que circundavam a dela. Eram as casas de seus filhos. Emocionada, com uma alegria que fazia verter dos olhos águas, exprimia o contentamento de ter os filhos por perto para poder zelar por eles. Neste momento, seu ofício se apresentava a nós de maneira enraizada. Percebíamos que o cuidado nascia no seio de sua descendência como uma continuidade ancestral. 
Essa trajetória retoma um desejo desobediente que nos exige transver o mundo desde outro lugar. Um estado que se estabelecia no contato da visita era o de deslocar-se do espaço comum para tatear o outro desde o seu ponto de vista, atuação, intervenção e do modo como se constitui no mundo. O tempo, por ali, é suspenso (aos nossos olhos acelerados), as relações são cunhadas na convivência profunda e no sentido de coletividade (interdependentes). A casa mais parecia uma oca indígena que acumula seus afetos entranhados na desigualdade que voeja por essas bandas. Tal percepção nasceu da observação do entorno e das relações de vida que, por sua vez, mostrou-se fortemente matriarcal. Desta paisagem, voltamos a atenção para a descolonização do inconsciente com ações propostas por Rolnik que nos provoca dizendo: "Não abrir mão do desejo em sua ética de afirmação da vida, o que implica em mantê-la o mais possível fecunda a cada momento, fluindo em seu processo ilimitado de diferenciação de formas e valores" (2018, p. 196).

As narrativas de Aroeira demostram que, distanciada de alguns imperativos que circundam a sociedade capitalista, patriarcal e colonialista, torna-se uma anciã que, conhecedora das raízes e suas propriedades medicinais abre espaço que desafia a lógica comum e a ordinária concepção de mundo. Dona Maria da Aroeira é um corpo-político desobediente uma vez que: desobedece as epistemologias emplacadas nas relações de mercado (tem sua banca de venda na feira no centro da cidade de Correntina-BA); desafia a lógica dos descentramentos familiares (quer seus filhos sempre por perto); ampara-se no saber ancestral herdado do seu pai (que certamente o herdou de outro parente ou ente próximo).

$\mathrm{O}$ ato de observação demostra um aprendizado pautado na oralidade e nas ações corporais que empunham todo o processo de identificação, colheita e preparação dos remédios a serem transformados em chás ou garrafadas 5 . Dona Aroeira foi iniciada ainda na infância nos saberes das propriedades das plantas e para quais problemas cada uma delas eram indicada. O processo de preparação de um remédio se dá como conhecimento empírico com o meio natural, ajuntado ainda aos afetos contidos nesta relação.

A memória desta condição nos recordou a concepção de Yi Fu Tuan:

$\mathrm{O}$ apego à terra do pequeno agricultor ou camponês é profundo. Conhecem a natureza porque ganham a vida com ela. [...] Para o trabalhador rural a natureza forma parte dele - e a beleza, como substância e processo da natureza pode-se dizer que a personifica. Este sentimento de fusão com a natureza não é simples metáfora. Os músculos e as cicatrizes testemunham a intimidade física do contato. A topofilia do agricultor está formada desta intimidade física, da dependência material e do fato de que a terra é um repositório de lembranças e mantém a esperança. (TUAN, 1983, p. 111).

Pensamos que a natureza também personifica Dona Maria, em uma "fusão" que está manifestada em seu corpo, no seu modo de viver e conviver com os outros, com a natureza e seus compostos. Mais adiante, ouvíamos sobre o fazer, seus modos de colheita, análogos a um "repositório de lembranças" que propunha uma metodologia relacionada a um saber muito próprio. Contava-nos que há muito cuidado no colher das ervas e das raízes para que a árvore não "sofra", e que a atenção ou não durante a recolha pode interferir nas propriedades do seu composto.

Dona Maria da Aroeira nos descrevia os processos de secagem no jirau, a sova da raiz de onde extraía o "remédio" e a imersão, no caso da garrafada. Ao descrever os seus processos ela ia retratando para nós um tipo de procedimento como uma metodologia curandeira essencial na sua vida, constituição cotidiana de um domínio fundamental e intenso que detinha, mas que ao seu entendimento era simples. Tais procedimentos nos fazem rememorar as palavras de Munduruku

\footnotetext{
${ }^{5}$ Garrafadas são misturas por meio de imersão das raízes com vinho branco ou água.
} 
Nosso povo sabe de onde veio. Sabe para onde vai. Tudo isso está escrito na tradição de nossa gente, desde o começo dos tempos. Não precisamos saber ler as letras escritas das cidades. Tudo está escrito na natureza. É preciso apenas saber ouvir. (2015, p. 23)

Seu saber adentrava a terra como uma raiz, que vertia para fora como cura tal qual uma raizremédio. Certamente a raizeira "sabe ouvir" as raízes, procedimento ancorado na ancestralidade indígena. De outro lado, ela esquiva-se de conversas quando tentamos saber procedimentos exatos da extração evidenciando uma zona limítrofe na qual podemos adentrar até um certo ponto. Sua ciência nos é evidenciada até este ponto. A despeito disso, a indagamos sobre quais raízes eram eficazes para fins específicos e prontamente ela nos indica as melhores alternativas. No momento ela estava sem raízes em estado de doação ou venda. Aliás, importante frisar, Conchita nos interpela na presença de Aroeira dizendo que ela mais oferta as raízes do que vende, o que fica confirmado pelos trejeitos que a senhora exprime através do corpo - olhos que se baixam, mas se agarram e acariciam, penas que balançam e a cabeça que confirma vagarosamente como quem vai lembrando de tais imagens. Isso demostra um oficio e uma dedicação pautada em um bem viver, em maneiras relacionais e partilhadas de estar no mundo. Trata-se de um ponto de fuga não pautado no imediatismo, mas em um modo de comunhão e devoção com o mundo.

Dona Maria personifica a Aroeira plantada no caminho da sua casa. Sua estrutura fixada no solo enraizando seu saber, ramificando seus remédios, como uma árvore e suas veias conducentes de solução, de amparo e de cura. As narrativas corporais de Dona Maria da Aroeira nos revelava as partes escondidas de suas raízes enterradas no cerrado baiano, parte de uma estrutura, como um órgão fundamental da sua comunidade.

Ao nos despedirmos, Conchita solicita a Dona Maria folhas de pimenta malagueta. Prontamente ela vai em busca retirar da primeira algumas folhas para presenteá-la. Não saímos do mesmo modo em que adentramos a porteira de sua casa. Fomos atravessados de muitas histórias e um fluxo de percepção que certamente a lógica cartesiana não consegue dimensionar. Há muito, viemos esboçando ideias de escritura dessa experiência de ganha corpo no presente como um modo de produzir conhecimento através de uma narrativa e do encontro com o outro, do encontro com outros corpos.

O desbravar de caminhos está em consonância com os encontros, os deslocamentos com a trajetórias que compõem experiências tal qual nos evidencia Guimarães Rosa. É no transcurso do tempo que tais experiências dimensionam e podem reverberar-se, transforma-se em movimento. Desse lugar, como docentes e artistas na contemporaneidade nosso encontro com tais narrativas visa dar espaço para outras percepções do mundo.

Trata-se, portanto, da possibilidade de perceber a memória atualizando-se perene ou atroz, de evidenciar e provocar pronuncias que se fazem corporalmente, individuais e coletivas, nos espaços intervalares, ou seja, nas encruzilhadas. São desses espaços que teremos a oportunidade de deflagrar espaços de experiências que possam provocar a produção artística e os modos de ensinar e aprender nos diversos contextos em que atuamos. A experiência que nos transpassa constitui-se presencialmente no corpo e nos desvelará possibilidades de intervenção de invenção no mundo vinculado ao contexto em que nos situamos, às histórias marginais que nos permeiam e a um sentido desobediente de viver o mundo comum. E pra não fugir à tradição, demarcamos a moral dessa travessia com as palavras de Davi Kopenawa ${ }^{6}$, sobre a terra.

\footnotetext{
${ }^{6}$ Citação de David Kopenawa extraído de KOPENAWA E ALBERT (2015, p. 468), de entrevista a F. Watson (Survival Internacional), Boa Vista, jul. 1992.
} 

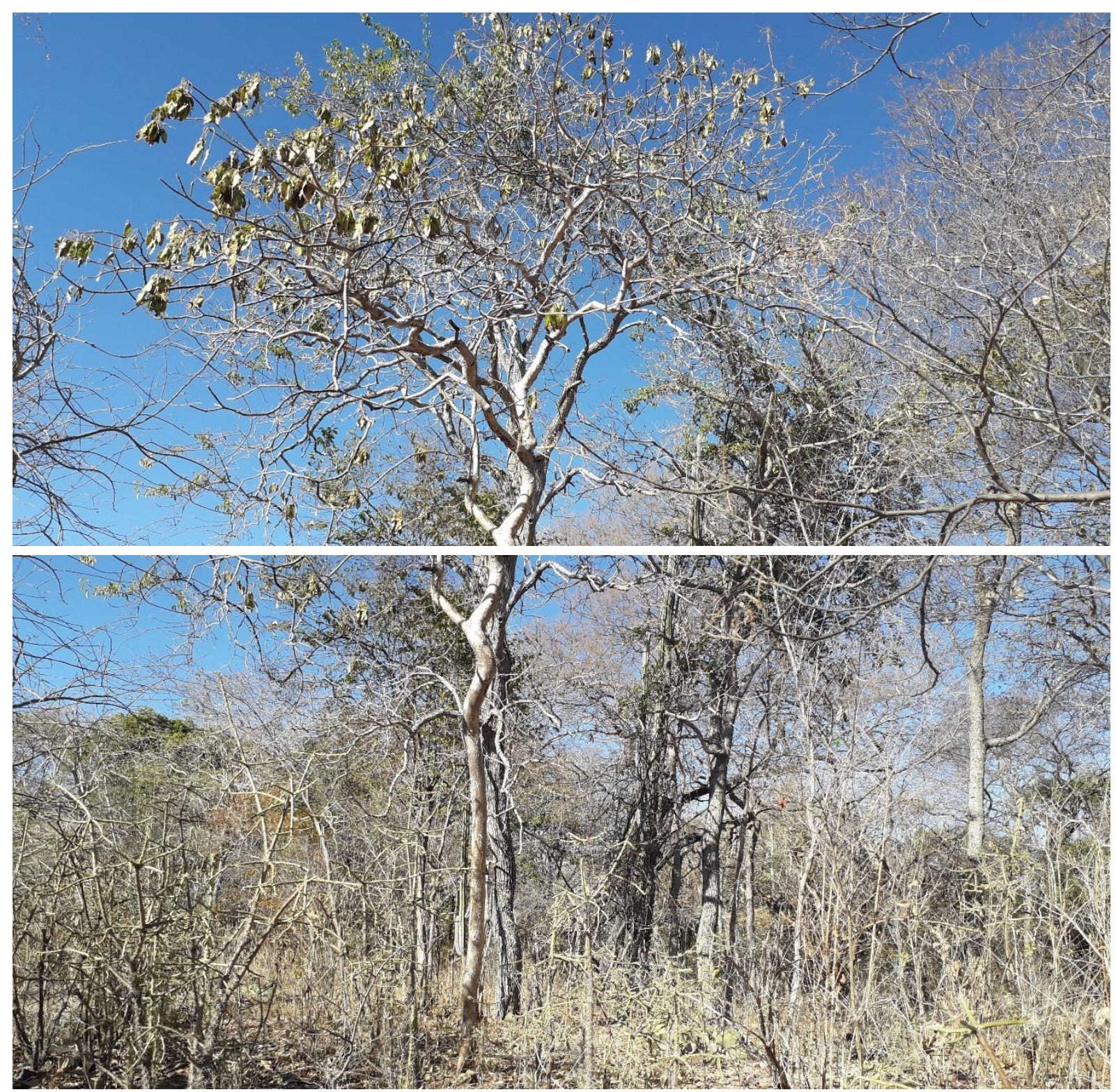

Figura 2 - Encontro-galho-tronco-raiz - Fonte: Arquivo dos autores

\section{Referências}

ACOSTA, A. O bem viver - uma oportunidade para imaginar outros mundos. Tradução Tadeu Breda. São Paulo: Autonomia Literária/Elefante, 2016.

BASSANI, T. S. Desterrados: transferência compulsória no Vale do São Francisco-BA. In: Daniel Santos Costa. (Org.). Corpo e diásporas performativas. Jundiaí: Paco e Littera Editorial, 2019.

COSTA, D. S. Corpo Mnemônico: encruzilhando corporalidades populares brasileiras e histórias de vida num(a) giro(a) performativo(a) decolonial. 2019. Tese (Doutorado em Teoria e Prática do Teatro) - Escola de Comunicações e Artes, Universidade de São Paulo, São Paulo, 
2019. Disponível em: 〈https://doi.org/10.11606/T.27.2019.tde-23072019-105829>. Acesso em: 28 nov. 2019.

COSTA, D. S. A experiência performática no giro de Folia de Reis. Revista Rascunhos caminhos da Pesquisa em Artes Cênicas - UFU, v. 4, n. 3, p. 47-65, jul./dez. 2017. Disponível em: 〈https://goo.gl/1QyVon>. Acesso em: 01 dez. 2019.

HALL, S. A identidade cultural na pós-modernidade. Tradução Tomaz Tadeu Silva e Guacira Lopes Louro. Rio de Janeiro: DP\&A, 2011.

KOPENAWA, D. e ALBERT, B. A queda do céu - palavras de um xamã yanomami. Tradução Beatriz Perrone-Moisés. São Paulo: Companhia das Letras, 2015.

MIGNOLO, W. D. El pensamiento decolonial - desprendimiento y apertura un manifiesto. In: CASTRO-GÓMEZ, Santiago, GROSFOGUEL, Ramón (Comp.). El giro decolonial: reflexiones para una diversidad epistémica más allá del capitalismo global. Bogotá - Colombia: Siglo del Hombre Editores; Universidad Central, Instituto de Estudios Sociales Contemporáneos y Pontificia Universidad Javeriana, Instituto Pensar, 2007.

MUNDURUKU, D. A história de uma vez: um olhar sobre o contador de histórias indígenas. In: MEDEIROS, Fabio Henrique Nunes; MORAES, Taiza Mara Rauen. Contação de histórias: tradição, poéticas e interfaces. São Paulo: Edições SESC São Paulo, 2015.

NEGREIROS, A. Maria Bonita - sexo, violência e mulheres no cangaço. Rio de Janeiro: Objetiva, 2018.

ROLNIK, S. Esferas da insurreição - notas para uma vida não cafetinada. São Paulo: n-1 edições, 2018.

SANTOS, B. de S.; MENESES, M. P. Epistemologias do Sul. São Paulo: Editora Cortez, 2010.

TAYLOR, D. $O$ arquivo e o repertório: performance e memória cultural nas Américas. Tradução de Eliana Lourenço de Lima Reis. Belo Horizonte: Editora UFMG, 2013a.

TUAN, Y. Topofilia - um estudo da percepção, atitudes e valores do meio ambiente. São Paulo: Difusão Editorial, 1980.

\section{Sobre os autores}

Daniel Santos Costa graduou-se em Dança (bacharelado) e em Artes - Dança (licenciatura) pela Universidade Estadual de Campinas, tem Mestrado m Artes da Cena (Unicamp) e Doutorado em Artes Cênicas (USP). É docente/pesquisador da Escola e Educação Básica - UFU e docente permanente nos programa de Mestrado Profissional em Artes (ProfArtes-UFU) e Mestrado em Artes Cênicas (PPGAC - UFU). Realiza pesquisas no campo das artes, cultura popular brasileira e educação.

E-mail: grdcosta@ufu.br. 
Tiago Bassani é Artista Visual, Professor do curso de Artes Visuais da Universidade Federal do Oeste da Bahia. Professor Formador II da Universidade Estadual da Bahia (UNEB-CAPESPARFOR). Doutorado em andamento em Artes Visuais (IA-UNICAMP). Mestre em Artes Visuais e Especialista em Artes Visuais, Intermeios e Educação, Bacharel e Licenciado em Artes Visuais, títulos pela Universidade Estadual de Campinas (UNICAMP). Desenvolve trabalhos em desenho, performance, vídeo, objetos e instalação.

E-mail: tiago.bassani@ufob.edu.br. 